\title{
A REMUNERAÇÃO DE PROFISSIONAIS DE TECNOLOGIA DA INFORMAÇÃO: UM ESTUDO SOBRE AS PRÁTICAS ADOTADÁS POR EMPRESAS DE INFORMÁTICA DO DISTRITO FEDERAL
}

\author{
THE REMUNERATION OF INFORMATION TECHNOLOGY \\ PROFESSIONALS: A STUDY ON THE PRACTICES ADOPTED BY \\ COMPUTER COMPANIES OF THE FEDERAL DISTRICT
}

Data de submissão: 09-04-2015 Aceite: 03-06-2015

Wesley Antonio Gonçalves ${ }^{1}$ Dalila Alves Corrêa ${ }^{2}$ José Antonio Monteiro Hipólito ${ }^{3}$ Antonio Carlos Giuliani ${ }^{4}$

\section{RESUMO}

A remuneração sempre foi considerada um aspecto crucial para as organizações reconhecerem e sistematizarem a agregação de resultados gerados pelos trabalhadores. É, também, um desafio, já que o assunto se mostra relacionado à sua produtividade e competitividade. Diante disso, este estudo teve como o objetivo analisar as práticas remuneratórias aplicadas por empresas do setor de informática, alocadas no Distrito Federal, em relação aos profissionais de Tecnologia da Informação (TI). Trata-se de um estudo qualitativo, exploratório e descritivo, realizado junto a 103 empresas filiadas e associadas à uma associação e/ou a um sindicato da área. A coleta de dados foi realizada por meio de um questionário padronizado e aplicado aos gestores-chave das referidas empresas. Os resultados mostraram que a remuneração funcional é a forma mais praticada pelas empresas que integraram a pesquisa e que há tendência de elas virem a praticar a remuneração estratégica. A pesquisa permitiu verificar, também, lacunas na atuação da gestão de pessoas das referidas empresas para alavancar práticas remuneratórias não convencionais, tal como a remuneração por competência - metodologia mais propícia para reconhecer e recompensar o trabalhador pelo valor agregado.

Palavras chaves: Remuneração e Recompensas, Remuneração de Profissionais de TI, Sistema de Remuneração, Gestão de Pessoas, Remuneração Estratégica.

\footnotetext{
${ }^{1}$ Possui graduação em Sistemas de Informação pela Faculdade do Noroeste de Minas - FINOM, mestrado em Administração pela Universidade Metodista de Piracicaba - UNIMEP e doutorado em andamento em Administração pela Universidade Metodista de Piracicaba - UNIMEP. Patrocínio. Minas Gerais. Brasil. E-mail: professorwesley@gmail.com

2 Possui graduação em Administração de Empresas pela Pontifícia Universidade Católica de Campinas - PUC, mestrado em Administração de Empresas pela Fundação Getulio Vargas - SP e doutorado em Administração pela Universidade de São Paulo USP. Atualmente é professora do Núcleo Permanente do Programa de Pós Graduação em Administração da Universidade Metodista de Piracicaba-UNIME e Coordenadora do MBA em Gestão de Pessoas e Desenvolvimento do Capital Humano da Faculdade de Gestão e Negócios/ UNIMEP. Piracicaba. São Paulo. Brasil. E-mail: dcorrea@unimep.br

${ }^{3}$ Possui graduação em Administração pela Universidade de São Paulo - USP, mestrado em Administração pela Universidade de São Paulo - USP e doutorado em Administração pela Universidade de São Paulo - USP. Atualmente é professor e coordenador do curso de pós-graduação Fundação Instituto de Administração - FIA. São Paulo. São Paulo. Brasil. E-mail: hipolitojam@usp.br

${ }^{4}$ Possui graduação em Administração pela Universidade Metodista de Piracicaba - UNIMEP, mestrado em Educação pela Universidade Metodista de Piracicaba - UNIMEP e doutorado em Educação pela Universidade Metodista de Piracicaba - UNIMEP. Atualmente é professor na área de Marketing e Coordenador do Programa de Pós-Graduação Mestrado Profissional - PPGA na Universidade Metodista de Piracicaba - UNIMEP e presidente da Comissão de Ensino de Pós-Graduação da UNIMEP. Piracicaba. São Paulo. Brasil. E-mail: giulianiag@unimep.br
} 


\section{ABSTRACT}

The remuneration has always been considered a crucial aspect for organizations recognize and systematize the aggregation of results generated by the workers. It is also a challenge, as it turns out related to its productivity and competitiveness. Therefore, this study had as objective to analyze the compensation practices applied by IT sector companies, allocated in the Federal District, in relation to Information Technology (IT) professionals. It is a qualitative study, exploratory and descriptive, carried out among 103 companies affiliated and associated with an association and / or a union area. Data collection was performed using a standardized questionnaire and applied to key managers of these companies. The results showed that the functional compensation is the form most widely practiced by companies that have integrated research and that there is a tendency for them to come to practice strategic compensation. Research has shown, too, gaps in performance management people of these companies to leverage unconventional compensation practices, such as compensation for competence-more suitable methodology to recognize and reward the worker by value.

Keywords: Compensation and Rewards, Compensation of Professionals, Compensation System, People Management, Strategic Compensation.

\section{INTRODUÇÃO}

O sistema de remuneração e recompensa é um assunto que sempre esteve presente nas discussões que envolvem a gestão de pessoas. Ultimamente, ele vem atraindo maior interesse da pesquisa acadêmica em função de seus impactos para alavancar a aquisição de competências humanas para as organizações - aspecto relacionado com a vantagem competitiva organizacional (HIPÓLITO, 2006). Desse modo, indagações sobre como remunerar o trabalho humano revelam preocupações sobre a forma de gerir e reconhecer pessoas e seus outputs (resultados).

Seguindo essa premissa, o presente artigo mostra os resultados de uma pesquisa que investigou a gestão remuneratória de profissionais de Tecnologia da Informação (TI) com vínculos empregatícios em empresas do setor de informática do Distrito Federal. Partiu-se do pressuposto de que os atuais desafios lançados para as empresas fornecedoras de TI fazem com que os seus gestores de remuneração e recompensa planejem e executem políticas capazes de atrair e reter bons profissionais da área. De modo semelhante, os profissionais de TI também são desafiados a buscar continuamente novos conhecimentos capazes de levá-los ao desenvolvimento de novas competências e de múltiplas habilidades que possam conferir maior mobilidade profissional e maiores níveis de recompensa e reconhecimento. O perfil deste profissional não é estritamente técnico, pois ele incorpora, também, atributos da gestão ao contribuir para as estratégias de negócios das empresas, assumindo papel relevante nesse contexto (GONÇALVES, 2012).

Assim, o objetivo do presente artigo consiste em analisar as práticas remuneratórias aplicadas por empresas do setor de informática do Distrito Federal. Para atingir a proposta, foi elaborado e aplicado um questionário padronizado aos gestores-chave de um grupo de empresas afiliadas e/ou associadas a uma Associação de Empresas de Tecnologia da Informação e/ou a um Sindicato da Indústria de Software ou Informática. Os dados foram analisados por meio do delineamento da pesquisa qualitativa que teve como intuito conhecer o fenômeno da prática de remuneração.

Estudar a remuneração desses profissionais auxilia a compreender a importância dos mecanismos de recompensa utilizados pelas empresas, conforme justificado por Zimpeck (1999) ao afirmar que, em uma sociedade constituída de acordo com os nossos padrões, o trabalhador atua estimulado por fatores como: ambição e orgulho profissional, necessidade de reconhecimento social e compensação financeira. A necessidade crescente das empresas pela TI fez crescer também a valorização por esses profissionais. 
Nesse contexto, este artigo versa sobre as práticas de remuneração e recompensas de um setor inovador e fornecedor de TI e de comunicação, apontando para a importância do tema, bem como visando contribuir para o avanço de pesquisas neste campo. Para isso, o texto está estruturado em três partes: esta introdução, uma breve apresentação acerca das principais abordagens conceituais sobre o assunto remuneração e a apresentação dos principais resultados da pesquisa realizada no conjunto das empresas de informática do Distrito Federal.

\section{FUNDAMENTAÇÃO TEÓRICA}

Autores como Dutra e Hipólito (2012), Marras (2012), Gheno (2011), Hanashiro et al., (2008), Pontes (2009), Silva (2005), Wood Jr. e Picarelli Filho (2004) e Scomazzon (2002) destacam a importância da gestão do sistema remuneratório pelas organizações, reconhecendo nesse sistema um elemento crucial para a constituição do seu capital intelectual. Nessa linha, Wood Jr. e Picarelli Filho (2004, p. 23) enfatizam que as tendências na gestão salarial são decorrentes das dimensões de mudanças da administração e negócios. Segundo os autores, os estágios de mudanças que vêm ocorrendo confirmam "a necessidade de as organizações reverem as suas metodologias de remuneração a fim de assegurar maior sucesso nas atividades de captar, reter e criar o capital intelectual que necessitam para manterem-se competitivas". Os autores afirmam, ainda, que o alinhamento do sistema de remuneração com o planejamento estratégico das organizações evidencia uma grande evolução quando se reconhece a importância e a necessidade de vinculá-lo a resultados profissionais e organizacionais. No contexto do processo evolutivo do sistema remuneratório, Dutra e Hipólito (2012) constatam que novas formas de remuneração e recompensas estão sendo implementadas e estas vêm atender aos novos modelos de organização do trabalho adotados pela modernização da gestão empresarial, tais como a gestão de pessoas com base em competências.

\section{Princípios da remuneração estratégica}

O sistema de remuneração estratégica tem seu foco nas pessoas. Segundo Wood Jr. e Picarelli Filho (2004), o colaborador, nesse sistema, percebe que ele faz parte da organização, sentindo-se valorizado por aquilo que realmente faz. Autores como Silva (2005) comparam o foco no indivíduo proposto pela remuneração estratégica como uma ponte na vida do colaborador e da organização. Segundo o autor, essa ponte se constrói da seguinte forma: em um primeiro momento, a organização formula uma estrutura organizacional, considerando o planejamento estratégico com foco não apenas no presente, mas também no futuro; em um segundo momento, a contribuição que o colaborador oferece à organização, tendo em vista as habilidades, os conhecimentos e as competências empregadas, passa a ser reflexo de como ele será remunerado.

Na percepção de Minamide (2008), o foco no indivíduo, dentre outros propostos pela remuneração estratégica, consiste em um conjunto de diferentes maneiras de remunerar os colaboradores. Segundo a autora, é possível estabelecer com a remuneração estratégica um "elo" entre o colaborador e a nova realização da organização. Com esse elo, os colaboradores sentem-se valorizados e melhor remunerados, reconhecendo a sua contribuição intelectual para o sucesso da organização e atendimento de metas estabelecidas.

Seguindo essas premissas e tendo como base os estudos realizados por Hipólito (2006), Wood Jr. e Picarelli Filho (2004), Fischer (2002), Ribeiro (1997) e Ledford (1995), é possível afirmar que uma das estratégias para alcançar o reconhecimento no mercado competitivo está ligada ao 
sistema de recompensa e desenvolvimento do colaborador, recompensando a contribuição do profissional. Os referidos autores comentam que um dos principais desafios a serem enfrentados pela gestão de pessoas reside no processo de capturar o valor agregado que elas produzem, ou seja, definir um valor para o trabalho realizado pelos colaboradores.

Dessa forma, os novos modelos de gestão empresarial estão alinhados à busca por inovação, competitividade e produtividade, exigindo cada vez mais dos colaboradores o desempenho de funções que extrapolam a reprodução de atividades prescritas em seus cargos. Espera-se que os colaboradores possam extrapolar limites e assumir atribuições relacionadas a iniciativas, à resolução de problemas e à criação de oportunidades e de crescimento de produção, tornando a empresa mais competitiva.

Partindo desse contexto, é necessário que a gestão de pessoas esteja alinhada com a crescente transformação nos processos de busca da inovação e da competitividade e reconheça na gestão da remuneração um desafio para gerir o capital humano.

\section{Componentes de remuneração e recompensas}

No Brasil, existem vários componentes de agregação da remuneração. Segundo Silva (2005), a maioria destes foi originada dos Estados Unidos da América (EUA), a partir dos sistemas de remuneração e das Consolidações das Leis Trabalhistas (CLT).

Já para Hanashiro et al. (2008), quando se faz comparação entre os componentes da remuneração brasileira com a original dos EUA, premissa de Silva (2005), o que se conclui é uma possível tendência da base dos componentes da remuneração, visando proporcionar mecanismos que promovam o desenvolvimento dos colaboradores, recompensando-os e, como consequência, ocasionando maior produtividade empresarial. Seguindo a mesma percepção, autores como Wood Jr. e Picarelli Filho (2004) dividem o termo recompensas em dois níveis distintos: (1) recompensa financeira (salário, férias etc.), subdivida em diretas e indiretas; e (2) recompensa não financeira (reconhecimento e estabilidade profissional). Para Wood Jr. e Picarelli Filho (2004), a remuneração é constituída de três componentes principais: (1) remuneração básica; (2) incentivos salariais e (3) benefícios, conforme o Quadro 1, apresentado a seguir.

\begin{tabular}{|c|c|c|}
\hline REMUNERAÇÃO BÁSICA & INCENTIVOS SALARIAIS & BENEFÍCIOS \\
\hline $\begin{array}{c}\text { - Salário fixo } \\
\text { - Remuneração direta }\end{array}$ & - Bônus & - Diversos \\
\hline
\end{tabular}

Quadro 1: Componentes da remuneração.

Fonte: elaborado pelos autores.

Para os mesmos autores, a proporção que cada componente assume na remuneração é variável de uma empresa para outra. O componente da remuneração básica refere-se ao pagamento fixo que o funcionário recebe na forma de salário mensal ou por hora, de acordo com a venda de seu trabalho. Trata-se da remuneração direta. Já os incentivos salariais são programas oferecidos para recompensar funcionários que apresentam bom desempenho por meio de bônus e participação nos resultados alcançados. Os benefícios, por sua vez, são concedidos por meio de diversos programas, como férias, seguro de vida, plano de saúde, refeições e transportes. Tais programas são também reconhecidos como remuneração indireta. 


\section{O conceito da remuneração funcional}

O sistema de remuneração funcional ou "tradicional" é determinado pela função que o colaborador exerce, ou seja, pelo cargo, que também é conhecido como "Plano de Cargos e Salário" (PCS) (WOOD JR.; PICARELLI FILHO, 2004; SOUZA, 2005). Para Hanashiro et al. (2008), a remuneração fixa ou funcional e o PCS constituem o tipo de remuneração mais popular e também o mais utilizado pelas empresas brasileiras.

Seguindo essas premissas, Hipólito (2006) comenta que, para uma boa compreensão sobre a remuneração funcional, primeiramente, é necessário entender o significado de "cargo", pois o termo abrange a acepção de "tarefa" e "posição". Ainda para o mesmo autor, a ideia de remunerar por cargo surgiu da lógica dos modelos propostos na década de Taylor e Ford com a produção em massa, quando do início da administração científica, para a qual a padronização, a repetição e a simplificação de atividades eram princípios a serem seguidos. Na mesma ótica, as ações individuais (tarefas executadas por um funcionário), formadas por grupos de colaboradores (diversos trabalhadores executando as mesmas atividades rotineiras e repetitivas), constituíam o valor pela produção (as tarefas padronizadas e realizadas pelos funcionários em uma determinada organização), a qual era equiparada a um cargo como todo, sendo remunerados de igual forma pelos trabalhos padronizados e idênticos (valor financeiro pago igualmente a todos os colaboradores da organização por sua ocupação e não por sua entrega, pelo valor agregado ou pelo volume de produção).

Autores como Souza et al. (2005) compartilham da visão de Hipólito (2006) ao apresentar a lógica de funcionamento deste sistema de remuneração: para cada posição de trabalho dos colaboradores de uma empresa, existe uma atividade funcional pela qual eles são responsáveis, e, uma vez que este "conjunto" de atividades é igual para todos os funcionários da empresa, nada mais justo do que remunerar todos igualmente, formando, assim, a premissa de remuneração por cargo ou o "Sistema de Remuneração Fixa ou Funcional".

\section{Pontos fortes da remuneração funcional}

Segundo Wood Jr. e Picarelli Filho (2004), muitas empresas ainda continuam utilizando a remuneração fixa ou funcional. Dentre as razões que justificam essa prática, destacam-se:

1 - como a remuneração funcional é adotada com um mecanismo de cargos e salários, as empresas que crescem rapidamente ou são passíveis de fortes mutações conseguem dar coerência interna à organização, pois, com esse método, as tarefas e atividades desempenhadas pelos colaboradores são detalhadas, o que atribui definições que ajudam a estruturar o trabalho, funcionando como uma espécie de manual de atribuições técnicas;

2 - retenção de mão de obra, já que o sistema funcional permite a equidade externa, o que acontece por meio de pesquisas salariais, podendo a empresa comparar seus salários com os praticados no mercado;

3 - com a equidade interna permitida pelo sistema funcional, a empresa consegue manter os salários estabelecidos a partir de regras aplicáveis a toda a organização, conferindo um sentido de justiça entre os colaboradores.

Nessa linha de raciocínio, Hipólito (2006) argumenta que essa modalidade não atende a todas as demandas existentes em um sistema de recompensa, apesar de ser um avanço na metodologia tradicional de administração salarial. Mesmo sendo mais flexível e mais coerente com a estratégia do negócio, esse sistema possui algumas limitações pertinentes à gestão de pessoas por meio de cargos. 
Os autores salientam, ainda, que, em alguns casos, frequentes nas organizações mais experientes, a adoção desse sistema consiste em uma "estruturação funcional por cargos e salários", alinhamento o planejamento estratégico organizacional.

O Quadro 2, exposto a seguir, apresenta uma síntese sobre a remuneração funcional.

\begin{tabular}{|c|c|c|c|c|}
\hline \multicolumn{5}{|c|}{ EM SÍNTESE } \\
\hline \multirow{8}{*}{ 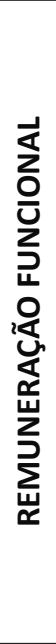 } & \multicolumn{2}{|c|}{$\begin{array}{l}\text { Componentes de agregação da re- } \\
\text { muneração }\end{array}$} & \multicolumn{2}{|r|}{$\begin{array}{l}\text { - Originada dos Estados Unidos } \\
\text { - Surgimento a partir dos sistemas de remuneração da CLT }\end{array}$} \\
\hline & \multicolumn{2}{|c|}{ Representações } & \multicolumn{2}{|r|}{ - Remuneração básica, Incentivos salariais e Benefícios } \\
\hline & \multicolumn{2}{|c|}{ Tipos de recompensas } & \multicolumn{2}{|r|}{ - Diretas e Indiretas } \\
\hline & \multirow[b]{2}{*}{ Aplicabilidades } & \multicolumn{2}{|c|}{ Diretas } & - Salário direto, Prêmios \\
\hline & & \multicolumn{2}{|c|}{ Indiretas } & $\begin{array}{l}\text { - DSR, Férias, Gratificação, Horas extras, 13ㅇ Salário, } \\
\text { Adicionais e Decorrência financeira }\end{array}$ \\
\hline & \multicolumn{2}{|c|}{ Participação nos lucros e resultado } & \multicolumn{2}{|r|}{$\begin{array}{l}\text { - Estratégia para enfocar critérios de produtividade, quali- } \\
\text { dade e lucratividade, conhecido como PLR }\end{array}$} \\
\hline & \multicolumn{2}{|c|}{ Remuneração Funcional } & \multicolumn{2}{|r|}{$\begin{array}{l}\text { - Também conhecido como "tradicional”, sendo determi- } \\
\text { nado pela função que o colaborador exerce, ou seja, pelo } \\
\text { cargo } \\
\text { - Também conhecido por “Plano de Cargos e Salário" (PCS) }\end{array}$} \\
\hline & \multicolumn{2}{|c|}{ Pesquisa Salarial } & \multicolumn{2}{|r|}{$\begin{array}{l}\text { - Destinada a verificar posições globais nas organizações } \\
\text { - Instrumento utilizado na busca pelo valor de cada cargo } \\
\text { na empresa }\end{array}$} \\
\hline
\end{tabular}

Quadro 2: Síntese sobre a remuneração funcional

Fonte: elaborado pelos autores

\section{Remuneração variável ou flexível}

A metodologia de Remuneração Variável (RV), de acordo com Paschoal (2007), é um sistema complementar de remuneração, baseado no desempenho do colaborador, que vem ganhando espaço na gestão de recursos humanos e na gestão estratégica. Conforme o autor, nos últimos anos, foram realizadas várias pesquisas que apresentaram as organizações adotando cada vez mais a remuneração variável.

Para Ledford (1995), a remuneração variável passa a ser uma estratégia da organização para mudar o cenário atual. Estratégia que Hipólito (2006) caracteriza como um elemento para ajudar as empresas a encontrarem "novos" mecanismos que regulem suas diferenciações salariais, em função, sobretudo, da ineficácia que os sistemas funcionais de remuneração vêm apresentando diante do intenso processo de mudança que assola o ambiente organizacional. Os autores enfatizam que a remuneração variável se alinha à expectativa de "recompensa por resultados", ou seja, com o efeito de retorno financeiro aos colaboradores, influenciando, por meio de incentivo, na produção, na inovação e no capital intelectual, fatores que impulsionam o crescimento da organização, conforme apresentado na Figura 2.

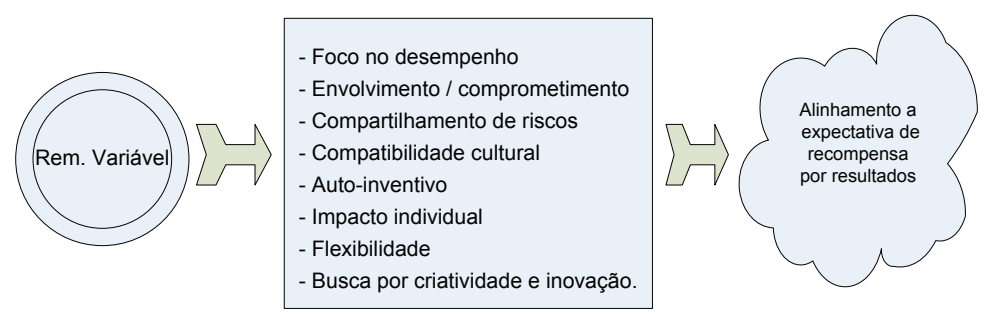

Figura 1: Alinhamento da remuneração variável Fonte: elaborado pelos autores com base em Hipólito (2006, p. 25). 
De modo geral, Fischer (2002), Hipólito (2006), Lopes (2007), Minamide (2008) e Ribeiro (1997) reconhecem que existe o risco de praticar esse modelo de remuneração de forma não produtiva, remunerando incorretamente, sem obter produtividade. Porém, segundo Lopes (2007), identificado um método que seja eficiente na medição dos desempenhos dos colaboradores, o sistema de remuneração passa a ser elemento vital para o desenvolvimento empresarial em busca da excelência, produtividade e inovação. Entretanto, a dificuldade de executar essa medição com objetividade e precisão tem sido o motivo da não adoção desse tipo de remuneração. Assim sendo, muitas organizações que adotam o sistema de remuneração por competência acabam, possivelmente, voltando ao sistema de remuneração funcional (tradicional).

Segundo Hipólito (2006), a empresa deve levar em consideração alguns cuidados quando introduzir a prática variável de remuneração (por competência), a qual deve se pautar pela consistência e pela coerência global entre as ações de recompensa, o discurso organizacional e aquilo que a organização busca e valoriza.

\section{Conceito de remuneração por habilidade}

Segundo Hipólito (2006), a proposta de remuneração por habilidade é focada na recompensa para a pessoa, desvinculando a rigidez típica do conceito de cargos. Para Minamide (2008), a remuneração é paga em função do conhecimento ou das habilidades certificadas.

Já Hipólito (2006) define a habilidade como o conjunto de conhecimentos que podem ser formalmente aprendidos e somados à aptidão pessoal. Por exemplo: uma pessoa que frequenta um curso de liderança adquirirá conhecimentos sobre o assunto, mas isso não garante que se tornará um líder. Para isso, é necessário que tenha aptidão para negociação, comunicação, trabalho em equipe, orientação para resultados e persuasão. Estes são exemplos de habilidades que, de acordo com Hipólito (2006), as empresas estimulam nos colaboradores.

Segundo Dutra (2002), essa estratégia se baseia em três pilares: (1) atitude das pessoas com relação ao dinheiro; (2) avaliação das habilidades das pessoas; e (3) avaliação de cargos com relação ao mercado. O Quadro 4, a seguir, apresenta uma síntese do sistema de remuneração variável.

\begin{tabular}{|c|c|c|}
\hline \multicolumn{3}{|r|}{ SÍNTESE DA REMUNERAÇÃO VARIÁVEL } \\
\hline \multirow{6}{*}{ 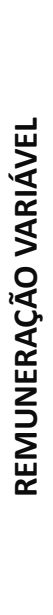 } & Metodologia & $\begin{array}{l}\text { - Sistema complementar de remuneração } \\
\text { - Baseando-se em desempenho do colaborador }\end{array}$ \\
\hline & Surgimento & $\begin{array}{l}\text { - A partir da pressão para realização do alinhamento estratégico, visando ao } \\
\text { equilíbrio interno e externo }\end{array}$ \\
\hline & $\begin{array}{l}\text { Remuneração por } \\
\text { competências }\end{array}$ & $\begin{array}{l}\text { - Foco voltado para a pessoa } \\
\text { - Valoriza a contribuição da pessoa } \\
\text { - Envolve conhecimento }\end{array}$ \\
\hline & $\begin{array}{l}\text { Diferenciação } \\
\text { da funcional }\end{array}$ & $\begin{array}{l}\text { - Relacionado à forma de recompensar o colaborador } \\
\text { - O foco é remunerar o colaborador pela contribuição entregue à organização }\end{array}$ \\
\hline & Dificuldades na adoção & - Mensuração do valor agregado por cada colaborador \\
\hline & $\begin{array}{l}\text { Remuneração } \\
\text { por habilidade }\end{array}$ & $\begin{array}{l}\text { - Focada na recompensa para a pessoa } \\
\text { - Valoriza os funcionários por sua capacidade e seu aperfeiçoamento } \\
\text { - Vinculados ao processo de certificação } \\
\text { - O funcionário deve demonstrar o domínio exigido para desempenhar a } \\
\text { função ao cargo } \\
\text { - O mais importante realmente são as habilidades desenvolvidas }\end{array}$ \\
\hline
\end{tabular}

Quadro 4: Síntese sobre remuneração variável ou flexível

Fonte: elaborado pelos autores 


\section{ASPECTOS METODOLÓGICOS}

Em uma pesquisa, é fundamental que seus métodos estejam relacionadas a determinadas crenças e/ou pressupostos que conduzem à realidade. É essencial, assim, que haja reflexão sobre a visão de mundo e de construção do conhecimento que a embasa (SACCOL, 2009).

Desse modo, com o intuito de observar a ontologia (como as coisas são) e a epistemologia (como o conhecimento do homem é construído), o presente estudo adotou o paradigma denominado de qualitativo (GODOI; BANDEIRA-DE-MELO; SILVA, 2010; POUPART; DESLAURIERS et al., 2008). Foi justamente esse paradigma de pesquisa, resultante da base epistemológica e ontológica, que concedeu o start ao design e definiu as técnicas de coleta e análise de dados empregadas (ORLIKOWSKI; BAROUDI, 1991; CROTTY, 1998).

Além do delineamento qualitativo, adotou-se a natureza descritiva (GODOI; BANDEIRADE-MELO; SILVA, 2010), cujo foco principal consiste em observar, registrar, analisar e correlacionar fatos ou fenômenos sem manipulá-los. Este tipo de pesquisa busca descobrir respostas para as perguntas: "quem?", “o quê?", "quando?", “onde?" e, algumas vezes, "como?", expondo características de determinada população ou de determinado fenômeno (COOPER; SCHINDLER, 2003, p. 31-131). Trata-se, também, de um estudo de natureza exploratória, baseado em teorias, sendo muito útil quando o pesquisador não tem uma ideia clara dos problemas que vai enfrentar durante o estudo.

Quanto ao método, trata-se de um estudo de caso (YIN, 2010), que consiste em uma pesquisa sobre um grupo ou uma comunidade que seja representativa do seu universo. Baseia-se em uma estratégia de pesquisa que quer examinar um fenômeno contemporâneo dentro de seu contexto.

O universo de pesquisa (campo empírico) voltou-se a empresas do ramo da informática sediadas no Distrito Federal. O público-alvo (amostragem) foi composto de 200 empresas, das quais 103 participaram do estudo.

Após a definição do método denominado de estudo de caso, foi elaborado e aplicado um questionário de caráter qualitativo pautado por um roteiro com perguntas estruturadas (GODOI; BANDEIRA-DE-MELO; SILVA, 2010). O processo de coleta de dados contou com o apoio logístico de uma associação e de um sindicato na distribuição eletrônica dos questionários.

Como o intuito de tratar e analisar os dados, aplicou-se a análise de conteúdo (BARDIN, 2011), considerando o contexto de origem dos dados, uma vez que o conteúdo não é o material bruto observado, mas o que emerge dele durante o processo de análise. Após este processo, procedeu-se à transcrição referente aos dados coletados. $O$ objetivo foi compreender os significados obtidos, levando em consideração as articulações utilizadas pelos sujeitos em suas respostas e as mensagens explícitas e implícitas que as acompanham (BARDIN, 2011).

Apesar da inclinação qualitativa para a condução dos dados coletados, os instrumentos e constructos utilizados na análise de conteúdo não excluíram a abordagem quantitativa concomitantemente, sendo os processos de codificação (e não seus resultados) fontes para as inferências (KRIPPENDORFF, 1990; BARDIN, 2011). Desse modo, os conceitos obtidos foram categorizados de acordo com as descrições dos respondentes, sendo levantadas as frequências de termos-chave enunciados nas respostas. A proposta consistiu na abordagem por unidades temáticas (KRIPPENDORFF, 1990; BARDIN, 2011), cujas categorias foram criadas a partir das próprias narrativas dos respondentes durante as entrevistas.

Em relação aos aspectos metodológicos utilizados, as estratégias e as instâncias filosóficas que nortearam este estudo, em síntese, são classificadas da seguinte forma: (a) quanto à natureza,: pesquisa qualitativa; (b) quanto ao gênero, empírico, teórico e metodológico; (c) quanto ao método, estudo de caso com aplicação de questionários; (d) quanto a sua lógica, indutiva; (e) quanto a sua base, interpretativista/qualitativa; (f) quanto a sua ontologia, interação sujeito-objeto; e (g) quanto a sua base epistemológica, construtivismo. 


\section{ANÁLISE DOS DADOS COLETADOS}

O questionário foi estruturado em quatro seções. A primeira abarcou um conjunto de informações sobre as empresas participantes do estudo, compreendendo a classificação da empresa em relação à atividade econômica, o número de funcionários, a data de fundação, os tipos de produtos/serviços prestados, a localização, a afiliação e a abrangência territorial do mercado de atuação. Já a segunda seção compreendeu as questões que identificam o respondente da pesquisa quanto ao cargo/função que ocupa na empresa, ao tempo de trabalho na função/cargo, ao nível atual da escolaridade e ao tempo de trabalho na empresa. A terceira seção, por sua vez, investigou a gestão de pessoas das empresas pesquisadas quanto às práticas, às ações, aos programas, às ferramentas e aos processos dessa gestão, uma vez que ela tem papel fundamental na proposição, na implantação e no desenvolvimento do sistema de remuneração das empresas. Este papel se torna mais relevante para organizações que almejam transformar a remuneração em um elemento de desenvolvimento e aprimoramento do capital intelectual dos colaboradores, ou seja, para empresas que buscam o alinhamento do sistema de remuneração com a estratégia, a estrutura, aos processos e as pessoas. As unidades de análise da gestão de pessoas que estabeleceram relações com a remuneração foram: processos de contratação de profissionais de Tl; processos de promoção de profissionais; processos de treinamento e desenvolvimento; e movimentação de carreira profissional. Por fim, a quarta seção do questionário compreendeu as questões que abordaram as dimensões da remuneração: orientações e critérios do sistema de remuneração, formas de recompensa, finalidades do sistema de remuneração, planejamento do sistema de remuneração e vínculo com a estratégia e com a atuação profissional.

\section{APRESENTAÇÃO E DISCUSSÃO DOS RESULTADOS}

As empresas participantes da pesquisa desenvolvem diferentes atividades econômicas no setor de informática, destacando-se a consultoria em hardware e em software. A consultoria em hardware envolve a comercialização de produtos de informática e a prestação de serviços em assistência técnica, enquanto que a consultoria de software auxilia as empresas a elaborarem projetos e desenvolverem softwares, atuando como representantes de software. Um pequeno número de empresas atua somente em atividades de banco de dados e distribuição on-line de conteúdo eletrônico (projeto, desenvolvimento e/ou suporte em banco de dados). A atuação das empresas abrange, em maior proporção, o mercado regional, compreendendo a capital (Brasília) e as cidades satélites do Distrito Federal.

O número de funcionários nessas empresas é pequeno, pois a maioria (90\%) emprega até 50 pessoas. Das 103 empresas, 80\% são afiliadas a um Sindicato da Indústria de Software ou Informática, e 20\% a uma Associação de Empresas de Tecnologia da Informação. Tais dados, somados a outros (não autorizados para divulgação), mostram que se trata de empresas de pequeno porte.

Quanto aos respondentes da pesquisa, verificou-se a presença de diretores e/ou presidentes, gerentes, gestores de pessoas e sócios-proprietários. Todos estes profissionais estão há mais de um ano trabalhando nos atuais cargos/funções. A maioria deles (51\%) possui escolaridade com nível superior, e a minoria (20\%) possui especializações e até mestrado e doutorado.

\section{A gestão de pessoas das empresas participantes}

Parte do desafio que as empresas contemporâneas enfrentam para implantar e estabelecer políticas de remuneração e recompensa aos seus colaboradores decorre da busca por 
equilibrar riscos e oportunidades de inovação na gestão de pessoas e não apenas da implantação técnica das novas ferramentas de remuneração.

Nesse sentido, esta pesquisa incluiu indagações sobre essa gestão, visando conhecer um pouco de sua realidade para apoiar inovações no sistema de remuneração e recompensa dos profissionais de TI. Ressalta-se que essa inclusão teve o objetivo de buscar alguns indícios sobre os seus procedimentos no sentido de amparar o conhecimento sobre os sistemas de remuneração por elas praticados, não se esgotando a sua atuação.

Em grande parte das empresas pesquisadas, o gerenciamento de pessoas está sob o encargo de um profissional que acumula esta função com outras da empresa, podendo ser ele um contador ou mesmo um prático ou técnico (com possibilidade de não possuir formação superior). É baixo o número de empresas (19\%) que têm uma administração de recursos humanos sistematizada. Cerca de $43 \%$ das empresas afirmam ter um departamento de pessoal que cuida das atividades de registros e controles sobre a movimentação de pessoas (entradas, saídas, afastamentos, licenças, dentre outras.)

Esse contexto remete não apenas à realidade das empresas, mas também à realidade operacional da administração de pessoas, que se caracteriza pelo cumprimento de processos voltados aos aspectos legais e trabalhistas das organizações pesquisadas. Tal realidade pode ser identificada por meio dos seguintes dados coletados:

- baixo investimento em programas de treinamento para os profissionais de TI (apenas $42 \%$ das empresas investem até $2 \%$ do seu faturamento, e $36 \%$ investem menos de $1 \%$ );

- baixa carga horária dedicada a tais programas (apenas 36\% das empresas desenvolvem mais de 50 horas semestrais e não ultrapassam 100 horas).

É interessante observar que esta carga horária poderá estar atendendo apenas à etapa de preparação do profissional ingressante e/ou à fase em que necessidades de reciclagem ocorrem em função de mudanças tecnológicas, operacionais, de gestão, dentre outras. Entretanto, se for considerado que $72 \%$ das empresas oferecem serviços de consultoria e desenvolvimento de software, essa carga de treinamento se mostra muito baixa e pode comprometer o desenvolvimento de capital humano das empresas em longo prazo, pois, para enfrentar a velocidade das mudanças na era das redes, das incertezas, da concorrência e de outros fenômenos ligados ao cenário da competitividade empresarial, as empresas devem oferecer oportunidades múltiplas de aprendizagem contínua para os seus profissionais (FISCHER, 1998).

Das empresas consultadas, $49 \%$ não tinham plano de carreira sistematicamente implantado. Afirmam que adotam o critério do atingimento de metas como o aspecto mais relevante para a promoção dos profissionais. Entretanto, mostraram expressivo interesse pelo critério da comprovação de aquisição de competências para orientar, futuramente, a mobilidade interna da carreira profissional.

Possuir certificação profissional para atuar em uma área do conhecimento não representa forte critério para promoção. Nesse sentido, os aspectos como "experiência" e "atingimento de metas" mostraram-se mais relevantes. Os processos de captação e seleção de profissionais de TI são considerados mais relevantes para a vantagem competitiva das empresas que priorizam critérios relacionados à experiência profissional dos candidatos. Novamente, a experiência pode ser vista como aspecto relevante para esses profissionais.

O fato de $61 \%$ das empresas afirmarem que adotam gestão de pessoas por competências indica não ocorrer de fato, tendo em vista a realidade das empresas quanto à sua gestão de pessoas, ou seja, à ausência de procedimentos, ferramentas e metodologias desta gestão que deem suporte para os sistemas remuneratórios com base em desempenho humano e na agregação de valor (DUTRA, 2001; 2009). Presume-se que o sentido "competências" tenha sido associado à experiência no atingimento de metas. 
Conforme amplamente destacado pela literatura da área de administração, a gestão de pessoas por competências considera a pessoa, seus conhecimentos, suas habilidades e a mobilização desses atributos para a geração de contribuição ou "entregas", constituindo-se em valiosos e potenciais fatores de agregação de valor à organização (DUTRA; HIPÓLITO, 2012). Esse modelo permite que o colaborador tenha a flexibilidade necessária para acompanhar as velozes mudanças do ambiente de trabalho, que sempre está a exigir novas competências, criatividade e inovação. No caso específico do profissional de TI voltado para o desenvolvimento de software, espera-se muita criatividade.

Assim, a valorização da competência é uma importante mudança de paradigma, que terá grande influência nos destinos das organizações e na forma como elas gerenciam o comportamento humano (MARRAS, 2012).

Nesse sentido, as noções que foram possíveis apreender sobre a gestão de pessoas das empresas pesquisadas levam a acreditar que tais empresas não são dotadas de uma gestão por competências, pois esta demandaria a aplicação de processos de mapeamento, formação, desenvolvimento e valorização das competências (FLEURY, 2002). Outra informação que reforça essa análise consiste na constatação da ausência de ferramentas para avaliar habilidades e competências em $77 \%$ das empresas pesquisadas.

\section{O sistema de remuneração e recompensa adotado pelas empresas pesquisadas e sua relação com os conceitos de remuneração estratégica}

Quanto ao sistema de remuneração adotado pelas empresas, observa-se que ele é orientado pela equidade ou pelo equilíbrio interno (o que deve levar em conta o equilíbrio entre os diferentes salários praticados internamente) e pelo equilíbrio externo (práticas das empresas de informática e de outras do mercado local e regional). Tal realidade segue a orientação comumente recomendada pela busca de equilíbrio nas dimensões interna e externa das práticas salariais (HIPÓLITO, 2006).

Além dessa orientação "básica", 83\% das empresas adotam outros critérios para definir o nível de pagamento dos profissionais, tais como:

- capacidade do colaborador para agregar valor à empresa (29\%);

- desempenho profissional diferenciado (27\%);

- existência de competências profissionais comprovadas (24\%).

As formas de recompensa praticadas pelas empresas são variadas: oferecimento de seguro de vida (para 29\% das empresas); plano de saúde diferenciado (para 17\%) e oferecimento de comissões e PLR (para 15\%).

Quanto à aplicação do sistema de remuneração diretamente ao colaborador, apuraramse as seguintes finalidades do sistema de remuneração:

- retenção de talentos (indicado por $27 \%$ das empresas);

- estímulo ao desenvolvimento contínuo dos mesmos (indicação de 11\% das empresas);

- aspecto diferencial para atrair e captar bons profissionais no mercado de trabalho (apontado por $23 \%$ das empresas).

Registrou-se, também, que $36 \%$ das empresas consideram como finalidade da remuneração "obter vantagem competitiva frente aos concorrentes", entendendo que essa vantagem decorreria em função de elas conseguirem atrair, desenvolver e reter os melhores profissionais do mercado.

Tais análises sugerem que as empresas reconhecem a existência de uma correlação entre sistema de remuneração, competências dos colaboradores e sucesso empresarial diante da concorrência, pois, segundo Dutra e Hipólito (2012), ao reconhecer e recompensar seus colaboradores por suas competências (valor agregado), o profissional de TI poderá extrapolar sua criati- 
vidade, aumentando a produtividade, inovando os produtos e serviços oferecidos ao mercado e, consequentemente, proporcionando competitividade para a organização.

Além das orientações que dão sustentação para o sistema de remuneração, $72 \%$ das empresas afirmam dar importância à conjuntura atual para planejar o sistema de remuneração, e $28 \%$ afirmam que incluem considerações sobre a realidade futura dos negócios para esta finalidade.

Das empresas pesquisadas, $92 \%$ reconhecem o papel de um sistema de remuneração para atingir a estratégia organizacional. Ainda que esse papel não tenha sido explorado na pesquisa, pode-se reconhecer que há uma relação entre sistema de remuneração, colaborador e atingimento estratégico, pois, conforme mencionado por Marras (2012), o princípio da remuneração estratégica baseia-se no planejamento de ações para recompensar os funcionários que colaboram com o avanço da produtividade da organização. Tal relação pode ser entendida no âmbito da busca por desenvolvimento contínuo e corretamente orientado pelas competências e habilidades que os colaboradores entregam para a organização.

Das empresas pesquisadas, $89 \%$ reconhecem que há um vínculo entre sistema de remuneração e os pedidos de desligamento de emprego (demissão voluntária), sendo os motivos mais apontados para essa ocorrência: salário inferior ao mercado, benefícios insuficientes e ausência de plano de carreiras - elementos integrantes de um sistema de remuneração e recompensas.

Conforme menciona Silva (2005), a visão da remuneração como foco na estratégia empresarial deve estar alinhada ao planejamento estratégico empresarial e estruturada em uma "ponte com o indivíduo". Assim, a contribuição que este oferece à organização passa a influenciar o modo como ele será remunerado, considerando-se o exercício das atividades sob sua responsabilidade e o seu papel na obtenção de vantagens competitivas frente aos concorrentes. A maior aproximação entre contribuição e remuneração deve acentuar a capacidade da organização em reter profissionais talentosos e motivados (DUTRA, 2008).

Seguindo essa estratégia, as empresas do setor de informática pesquisadas intencionam reconhecer a remuneração dos seus profissionais como um recurso estratégico para obter vantagens competitivas. Essas práticas são condizentes com as premissas de Fischer (2002), Hipólito (2006) e Ribeiro (1997), quando mencionam as estratégias para alcançar o reconhecimento no mercado competitivo, entendendo o sistema de recompensa e desenvolvimento do colaborador como um mecanismo para recompensar a contribuição do profissional.

Os resultados obtidos nesta pesquisa reforçam a ideia de Hipólito (2006), que salienta a dificuldade de implantar um sistema de remuneração por competência. A dificuldade encontrase justamente em estabelecer uma medida capaz de recompensar esse valor agregado. Embora ainda não encontrada na literatura atual uma teoria sólida, que consiga definir e sistematizar o termo "valor agregado" na gestão de pessoas, acredita-se que a adoção de metodologias ou ferramentas de avaliação estruturadas pode auxiliar na captura do valor agregado (entrega de contribuição) no processo de competências e, consequentemente, constituir-se em referencial útil para apoiar decisões de natureza remuneratória.

Além disso, constatou-se que os sistemas de remuneração das empresas pesquisadas contam com recompensas como "seguro de vida", "plano de saúde" e "comissões", mas que a Participação nos Lucros e Resultados (PLR) ainda é adotada apenas por um número muito baixo das empresas participantes.

Em um setor de grande inovação tecnológica, como o da informática, a adoção de PLR ou de outras formas de remuneração variável, apoiadas em indicadores de desempenho de qualidade, produtividade ou lucratividade, pode constituir-se em outro mecanismo importante para aproximar a gestão de recompensas da estratégia da organização e, com isso, aumentar a capacidade da empresa atrair, reter e mobilizar profissionais na direção de seus objetivos (HIPÓLITO, 2006). 


\section{CONSIDERAÇÕES FINAIS}

Neste estudo, objetivou-se analisar as práticas remuneratórias aplicadas por empresas do setor de informática alocadas no Distrito Federal, dando ênfase à remuneração de profissionais de Tecnologia da Informação (TI). O intuito foi alcançado ao desvelar que o sistema de remuneração adotado por um grupo formado por 103 empresas de informática do Distrito Federal apresenta elementos da remuneração estratégica, evidenciando tendências deste sistema vir a ser consolidado, em futuro próximo, em tal contexto.

Percebe-se no decorrer das análises que, para que a remuneração estratégica das organizações do setor de informática pesquisadas se concretize, a gestão das empresas pesquisadas deverá alinhar o planejamento estratégico empresarial à definição dos sistemas de remuneração mais adequada para a realidade conjuntural.

Dentre os avanços e as contribuições obtidas pelo presente estudo, destaca-se o conjunto de dados e informações gerados sobre o assunto e o contexto pesquisado, uma vez que não foram encontradas publicações disponíveis ao público quanto às práticas remuneratórias aplicadas por empresas do setor de informática, alocadas no Distrito Federal, em relação aos profissionais de TI. Destaca-se, ainda, a importância de as empresas do setor de informática dispensarem maior atenção à sua gestão de pessoas, com ênfase no processo remuneratório - uma vez que este tem papel crucial para atração e fidelização de um corpo de profissionais qualificado e disposto a aprender continuamente. Nesse sentido, tal movimento pode se constituir em estratégia para aumentar a competitividade empresarial na busca de geração de valor agregado.

Como limitação deste estudo, percebe-se a falta de contato presencial com os respondentes (sujeitos da pesquisa), fator que levanta o pressuposto de possíveis dúvidas ou de não compreensão do objetivo da pergunta para responder as questões ontológicas ligadas às práticas de gestão de pessoas (epistemologia técnica e humana), separando-as das questões vinculadas ao campo do profissional (epistemologia organizacional e profissional) ou unificando-as. Outro elemento que indica uma possível fragilidade se relaciona ao fator regional, devido ao estudo ter elegido somente empresas de uma mesma região do país (campo empírico).

Como sugestão para novas pesquisas, recomenda-se reaplicar o instrumento de coleta de dados em outras regiões (estados) ou micro regiões dos estados, assim como realizar pesquisas no intuito de desenvolver o mapeamento e a validação de competências nas empresas de informática. Também se recomenda uma investigação que possa desenvolver o constructo "agregação de valor" na gestão de pessoas.

\section{REFERÊNCIAS}

BARDIN, L. Análise de conteúdo. 70. ed. São Paulo: Almedina, 2011.

CERVO, A. L.; BERVIAN, P. A. Metodologia científica. São Paulo: Pearson Prentice Hall, 2002.

COOPER, D. R.; SHINDLER, P. S. Métodos de pesquisa em administração. Porto Alegre: Bookman, 2003.
CROTTY, M. The foundations of social research: meaning and perspective in the research process. London: Sage, 1998.

DUTRA, J. R.; HIPÓLITO, J. A. M. Remuneração

e Recompensas. São Paulo: Atlas, 2012.

DUTRA, J. S. Competências: conceitos e instrumentos para a gestão de pessoas na empresa moderna. São Paulo: Atlas, 2009.

DUTRA, J. S. R. Gestão por Competências. São Paulo: Gente, 2001. 
DUTRA, J. S. R. Competências: Conceitos, Métodos e Experiências. São Paulo: Atlas, 2008.

FISCHER. Um resgate conceitual e histórico dos modelos de gestão de pessoas. In: Fleury, M., (org.) As pessoas na organização. São Paulo: Gente, 2002.

FLEURY, M. T. L. A gestão da competência e a estratégia organizacional. In: FLEURY, M. T. L. (cood.). As pessoas na organização. São Paulo: Gente, 2002.

GHENO, R.; BERLITZ, J. Remuneração estratégica e pacote de benefícios: um estudo de caso aplicado ao nível operacional de uma multinacional. Rev. Adm. UFSM, Santa Maria, 2011. 268-287.

GODOI, K. C.; BANDEIRA-DE-MELO, R.; SILVA, A. B. Pesquisas Qualitativa em Estudos Organizacionais: Paradigmas, Estratégias e Métodos. 2. ed. São Paulo: Saraiva., 2010.

GONÇALVES, W. A. O Profissional de T.I. Revista Espírito Livre, Vitória, n. 37, p. 14-22, abril 2012.

HANASHIRO, D. M. M.; TEIXEIRA, M. L. M.; ZACCARELLI, L. M. Gestão do fator humando: uma visão baseada em Stakeholders. 2. ed. São Paulo: Saraiva, 2008.

HIPÓLITO, J. A. M. Administração Salarial. São Paulo: Atlas, 2006.

KRIPPENDORFF, K. Metodología de análisis de contenido: teoría y práctica. [S.I.]: Editorial Paidós, 1990.

LEDFORD, G. E. Creating High Performance Organization Practices and of Employee Involviment and Total Quality Management in Fortune 1000 Companies. San Francisco: Jossey-Bass, 1995.

LOPES, M. C. D. Um estudo sobre remuneração por habilidades e competências, 2007. Disponivel em: <http://carreiras. empregos.com.br/comunidades/rh/fique por_dentro/260901-rh_remuneracao_ competencias.shtm>. Acesso em: 20 set. 2010.

MARCONI, M. D. A.; LAKATOS, E. M. Fundamentos de metodologia científica. In Fundamentos de metodologia científica. São Paulo: Atlas, 2010.

MARRAS, J. P. Remuneração estratégica. Rio de Janeiro: Elsevier, 2012.

MINAMIDE, C. H. Sistemas de Remuneração Tradicionais e Remuneração Estratégica. Disponivel em: <http://carreiras.empregos. com.br/carreira/comunique_se/col_ leitor/120404-sistemas_remuneracao_camila. shtm>. Acesso em: 20 out. 2010.

ORLIKOWSKI, W.; BAROUDI, J. Studying information technology in organizations: research approaches and assumptions. Information Systems Research, v. 2, n. 1, p. 1-28, March, March 1991. 1-28.

PASCHOAL, L. Administração de cargos e salários: manual prático e novas metodologias. 3. ed. Rio de Janeiro: Qualitymark, 2007.

PONTES, B. R. Administração de Cargos e Salários. 9. ed. Rio de Janeiro: Atlas, 2009.

POUPART, J. et al. A pesquisa qualitativa: enfoques epistemológicos e metodológicos. Petrópolis, Rio de Janeiro: Vozes, 2008.

RIBEIRO, G. M. Remuneração variável. Revista Parceria em qualidade, Rio de Janeiro, v. 5, n. 21, p. 40-41, 1997.

RYCHARDSON, R. J. Pesquisa social: Métodos e técnicas. São Paulo: Atlas, 1999.

SACCOL, A. Z. Um retorno ao básico: compreendendo os paradigmas de pesquisa e sua aplicação na pesquisa em administração. Rev. Adm. UFSM, Santa Maria, 2009. 250-269.

SCOMAZZON, E. Programa de participação nos lucros ou resultados nas empresas metal-mecânica e de Material elétrico da 
região serrana do estado do RS: um estudo exploratório. 201 f. (Dissertação) Programa de Pós-Graduação em Administração. Universidade Federal do Rio Grande do Sul. Porto Alegre. 2002.

SILVA, M. O. Sistemas modernos de remuneração. Rio de Janeiro: Qualitymark, 2005.

SOUZA, M. Z. A. et al. Cargos, Carreiras e Remuneração. FGV Managament, Rio de Janeiro, 2005.

STEWART, T. A. A Riqueza do Conhecimento: O Capital Intelectual e a Organização do Século XXI. Rio de Janeiro: Campus, 2002.

WOOD JR, T.; PICARELI FILHO, V. Remuneração por habilidades e por competências: preparando a organização para a era das empresas de conhecimento intensivo. São Paulo: Atlas, 2004.

YIN, R. K. Estudo de Caso: planejamento e método. Porto Alegre: Bookman, 2010.

ZIMPECK, B. G. Administração de salários: sistemas e métodos de análise e descrição de cargos, pesquisa e escalas salariais, avaliação de desempenho, avaliação de cargos. 9. ed. São Paulo: Atlas, 1999. 